Vol. 11 (4): 759-766 (2021)

\title{
FOOD WASTE MANAGEMENT STRATEGIES IN FOOD SUPPLY CHAIN
}

\author{
Aijaz Hussain Soomro' ${ }^{1}$, Nida Shaikh ${ }^{1}$, Tahseen Fatima Miano ${ }^{1 *}$, Asadullah Marri ${ }^{1}$, \\ Shahzor Gul Khaskheli ${ }^{1}$, Dileep Kumar ${ }^{1}$ \\ ${ }^{1 *}$ Sindh Agriculture University, Institute of Food Sciences and Technology, Tandojam 70060, Sindh, Pakistan;
}

*Corresponding Author Tahseen Fatima Miano, e-mail: tahseenfm@yahoo.com;

Received June 2021; Accepted July 2021; Published August 2021;

DOI: $\underline{\text { https://doi.org/10.31407/ijees11.413 }}$

\begin{abstract}
The increasing food waste is considerably gaining attention to food growers, processors, scientists and consumers to explore the ways that can alleviate the risks of food waste. The objective of this study is to discover effective food waste management strategies to improve existing food waste management approaches in food production areas. According to the Food and Agriculture Organization (FAO) revealed that one third of all food produced is wasted every year, worldwide owing to insufficient production, processing, and storage tactics. This frequent and persistent food waste is not merely generating food security issues but also creating economic problems, impacts on profitability in food supply chain, loss of food waste management cost and hunger. Therefore, securing the food from waste from various stages of food processing throughout the food supply chain is important for understanding. This review paper focused on the key factors in food supply chain to food waste and food waste preventing strategies regarding existing sustainable food waste utilization approaches.
\end{abstract}

Keywords: Food waste, sustainability, food supply chain, waste management. 